\title{
Assessing the Water Footprint of Irrigated Rice Production for Doho Rice Irrigation Scheme, Butaleja District, Uganda
}

\author{
Catherine Naula ${ }^{1}$, Yoronimo Oketcho ${ }^{1}$ \\ 1 Department of Water Resources and Mining engineering, \\ Busitema University, P.O Box 236, \\ Tororo - Uganda
}

\begin{abstract}
Water footprint assessment addresses the issues of freshwater scarcity and pollution which is limited to considering human activities that impact the quantity or quality of freshwater within a catchment. Water footprint" is an indicator of water use in relation to crop yield. It generally breaks down three components depending on water resources i.e. green, blue, grey water. The water footprint was determined using the climatic data of Mbale meteorological station (2002 to 2018). This study quantified the green, blue and grey water footprints of rice production for Doho Rice Irrigation Scheme found in Butaleja district in Eastern Uganda. Aqua crop model was used for simulating the crop water use and the yield which takes into account the daily soil water balance and climatic conditions. In addition, the water pollution associated with the use of nitrogen fertilizer in rice production is estimated. The study included two growing seasons of rice. The green water footprint was $1078 \mathrm{~m}^{3} /$ ton and $922.57 \mathrm{~m}^{3} /$ ton for the first and second season respectively. The blue water footprint was $141 \mathrm{~m}^{3} /$ ton and $4812.16 \mathrm{~m}^{3} /$ ton for the first and second season respectively. The grey water footprint was $129.87 \mathrm{~m}^{3} /$ ton and $143.39 \mathrm{~m}^{3} /$ ton for the first and second season respectively. Deficit irrigation was considered majorly to policy makers in formulating water management strategies to reduce water footprint. Hence, these results are useful for paddy rice water management, specifically establishment of water saving policy.
\end{abstract}

Key words: Deficit irrigation, ,greywater, water footprint, water pollution,

\section{INTRODUCTION}

Human activities devour and pollute a lot of fresh water world over. According to [1], most of the water consumption occurs in agricultural production, but there are also significant water volumes consumed and polluted in the industrial and domestic sectors. Water consumption and pollution can be linked with specific activities, such as irrigation, bathing, washing, cleaning, cooling and processing [2]. Total water consumption and pollution are generally regarded as the sum of a multitude of independent water demanding and polluting activities. Little attention has been paid to the fact that, in the end, total water consumption and pollution relate to what and how much communities consume and to the structure of the global economy that supplies the various consumer goods and services [3] . Until the recent past, there have been few thoughts in the science and practice of water management about water consumption and pollution

\author{
Erion Bwambale ${ }^{2 *}$ \\ 2 Department of Civil Engineering, \\ Pan African University, \\ Institute for Basic Sciences Technology and Innovation \\ (PAUSTI), P.O. Box 62000, Nairobi, Kenya
}

along whole production and supply chains. As a result, there is little awareness regarding the fact that the organization and characteristics of a production and supply chain strongly influence the volumes (and temporal and spatial distribution) of water consumption and pollution that can be associated with a final consumer product. [3] have shown that visualizing the hidden water use behind products can help in understanding the global character of fresh water and in quantifying the effects of consumption and trade on water resources use. The improved understanding can form a basis for a better management of the globe's freshwater resources.

Water footprint (WF) is a recently introduced concept of estimating the amount of water needed for production. It is measured as an indicator of the water volumes consumed or polluted[4]. In agriculture, the water footprint of a given crop is the ratio of plants potential evapotranspiration to the final crop yield. Instead of measuring the volume of agricultural water used, which traditionally only includes irrigation water, the WF is an indicator measuring the volume of water used during the whole growing cycle at the point of production. It quantifies the impact of natural endowment and climate factors on the agricultural water use efficiency, including natural factors, such as the latitude and longitude, soil types, climate factors like precipitation, maximum and minimum temperatures, etc [5]. This ratio can be used as an index of irrigation water rational use. The total volume of agricultural water consumed for crop production is the sum of the blue, green and grey water footprints [6]

Irrigation schemes in Uganda are under expansion which is expected to increase the Water Footprint of the schemes [7]. Hence it is crucial to determine the Water Footprint that will guide the formulation of strategies to optimize production in irrigated agriculture.

\section{MATERIALS AND METHODS}

DRIS is located in Maseru village, Mazimasa sub-county, Butaleja District in Eastern Uganda, about 40km south west of Mbale which is the nearest big town. Its geographical location is $0^{\circ} 57^{\prime} 10.98^{\prime \prime}$ 'North and $34^{\circ} 1$ ' $48.78^{\prime}$ ' East. DRIS comprises of 10 blocks with a total acreage of 2500 ha [8]. 


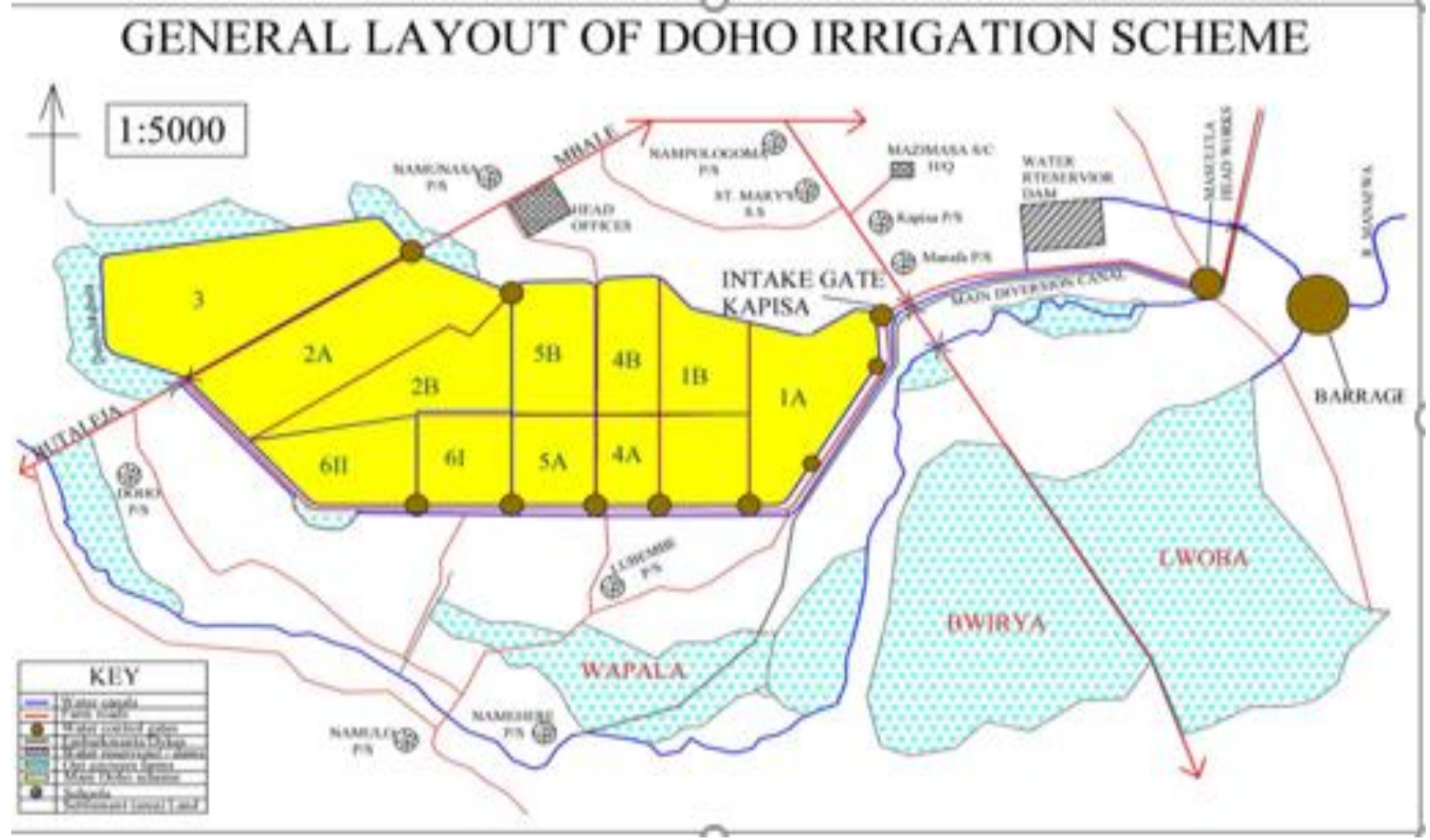

Figure 1: The general layout of DRIS adapted from:[9]

\section{Data acquisition techniques}

The data for this research was collected from both primary and secondary sources.
Primary data was collected, first-hand information through experiments, and taking the required measurements. Secondary data was sourced from books, journals, magazines, and internet.

Table 2: Data sources and types

\begin{tabular}{|l|l|}
\hline Datasets & Sources \\
\hline Primary data & \\
\hline Soil data & In-situ \\
\hline Initial water conditions & DRIS office \\
\hline Crop type & From the field \\
\hline Water samples & From the field \\
\hline Discharge measurement & Field \\
\hline Secondary data & \\
\hline $\begin{array}{l}\text { Climate data (rainfall, wind speed, solar radiation, average relative } \\
\text { humidity, Maximum and minimum temperature) }\end{array}$ & MWE (Mbale Meteorological station) \\
\hline
\end{tabular}

\section{Determining the pollution potential loading on river} Manafwa downstream of the rice fields.

Water samples were collected and analyzed. The sample points were taken at the intake point (headworks), to the irrigation canal, in the rice field (Block 6B/6A) and at the outfall of the drainage water to the river. The parameters tested were Nitrogen, Phosphorus, COD, pH, Magnesium and Calcium as the main composition of chemicals applied to the fields.

Analysis of the water samples was carried out from MWEMbale laboratory.

Table 1: water quality parameters tested and methods used

\begin{tabular}{|l|l|}
\hline Parameter & Method \\
\hline Nitrogen & TNT Persulfate Digestion Method \\
\hline Phosphorous & Spectrophotometer DR 3900 \\
\hline Magnesium & Titration using EDTA \\
\hline Calcium & Titration using EDTA \\
\hline $\mathrm{pH}$ & Using a pH meter \\
\hline $\mathrm{COD}$ & Dichromate Reactor Digestion Method \\
\hline
\end{tabular}


Determining the quantity of water diverted from river Manafwa

A current flow meter was used to measure the discharge using the flow area method.

\section{Materials and equipment used.}

Current flow meter, rods, wading, notebook, pen, tape measure.

\section{Procedure of measurement.}

i. A uniform section along different points of the stream was identified.

ii. A tape measure was used to determine the width of the stream.

iii. A propeller was submerged into the stream at about half way the depth at uniform interval across the section against the direction of flow.

iv. The current meter was started to record the sounding (depth at the particular width point) to determine the area and the revolutions (rpm) to determine the velocity.

v. To obtain the rate of flow, the average crosssectional area of the stream (m) was multiplied by the average stream velocity $(\mathrm{m} / \mathrm{s})$ and the answer is the rate of flow in cubic meter per second.

$$
Q=V_{\text {mean }} A
$$

Where $\mathrm{Q}$ is the flow rate, $\mathrm{V}$ is the velocity, $\mathrm{A}$ is the crosssectional area, $\mathrm{L}$ is the length of the test section.

The amount of water used in a season was calculated using the equation below.

$$
\text { Total amount of water }=Q * T
$$

\section{Grey water footprint. \\ Quantifying dilution water requirement}

GWF is calculated as the chemical application rate per hectare times the leaching fraction divided by the maximum acceptable concentration minus the natural concentration for the pollutant considered [10].

$$
\boldsymbol{L}=\propto * \boldsymbol{A R} \text { (Mass/time) }
$$

Where:

$\mathrm{L}$ is the pollutant load, $\propto$ is the leaching runoff fraction (chemicals that reach fresh water body), AR is the Application rate of chemical substances to the field.

$$
\boldsymbol{G} \boldsymbol{W} \boldsymbol{F}=\frac{\boldsymbol{L}}{\boldsymbol{C}_{\max }-C_{\text {nat }}}(\text { Volume } / \text { time })
$$

$\mathrm{L}$ is the pollutant load released into the water body, $C_{\max }$ is the permissible concentration of pollutant according to national regulations, $C_{n a t}$ is the natural concentration of the receiving water body. Assume $C_{\text {nat }}$ to be zero.

\section{Leaching runoff fraction}

$$
\propto=\propto_{\min }+\left[\left(\frac{\sum S i * W i}{\sum W i}\right] *\left(\alpha_{\max }-\alpha_{\text {min }}\right)\right.
$$

Where $\alpha_{\max }$ is the maximum leaching fraction, $\alpha_{\min }$ is the minimum leaching fraction, $\mathrm{Si}$ is the score for each leaching runoff potential, Wi is the weight of the factor. But $\mathrm{S}$ is low =zero.

Therefore $\alpha=\alpha_{\min }$

\section{Quantification of the green and blue water footprint of} rice.

Aqua Crop 6.0 model was used for analysis because of its ability to simulate yield response to water.

\section{Input data requirement of Aqua Crop Model}

The important inputs were weather data, soil characteristics, crop type and management practices, which include field management and irrigation management.
A. climate data
i. Comprised of minimum $\left(\mathrm{T}_{\mathrm{n}}\right)$ and maximum $\left(\mathrm{T}_{\mathrm{x}}\right)$ temperature,
ii. wind speed
iii. rainfall depth
iv. reference evapotranspiration $\left(\mathrm{ET}_{0}\right)$
v. carbon dioxide concentration.

The climatic data used was for Mbale meteorological station from 2003-2018.

B. Crop

i. Limited set crop development and production parameter which include phenology and life cycle length).

ii. Calendar of growing cycle. The number of growing days were 150 .

C. Management

i. Irrigation type. Surface irrigation (basin was considered for the paddy rice). For irrigation purposes, there are three methods provided by Aqua Crop, viz. net irrigation water requirement, irrigation schedule and generation of irrigation schedule.

ii. Field surface practices- surface runoff, soil bunds

D. Soil

i. Soil profile. The soil profile considered was 1 because of maximum root depth.

ii. Characteristics of soil horizon. It comprised of silt clay loam soil.

iii. Soil surface

iv. Capillary rise

v. Ground water

E. Simulation data

i. Simulation period linked to the growing season

ii. Initial conditions 


\section{Net Irrigation Requirement}

The rice is grown on silt loam clay soil. The purpose was to ensure that the entire soil profile is at field capacity and that crop canopy development is never affected by water stress. Correct crop file was selected (rice crop). Then, a net irrigation requirement file with 0\% RAW (allowable root zone depletion) was created. The simulation started one day after transplanting (Not linked to growing cycle) for each run. Initial condition at field capacity for each run. The project was run and yield and net irrigation requirements were assessed for every season.

$$
I R n=E T C-P e
$$

Where $\mathrm{IR}_{\mathrm{n}}$ is the net irrigation requirement, $\mathrm{ET}_{\mathrm{c}}$ is the Crop Evapotranspiration and $\mathrm{P}_{\mathrm{e}}$ is the effective rainfall.

\section{Crop water requirement}

The water requirement of a crop is the total quantity of water required from its sowing time to harvest. The influence of the climate on crop water needs was calculated by the reference Crop Evapotranspiration $\left(\mathrm{ET}_{0}\right)$. The $\mathrm{ET}_{0}$ is usually expressed in millimeters per unit of time, e.g. $\mathrm{mm} /$ day, $\mathrm{mm} / \mathrm{month}$, or $\mathrm{mm} / \mathrm{season}$. The relationship between the reference grass crop and the crop actually grown is given by the crop factor, $\mathrm{K}_{\mathrm{c}}$, as shown [11]

$$
\boldsymbol{E T C}=\boldsymbol{K C} * \text { ETo }
$$

\section{Estimation of Effective rainfall}

Effective rainfall is that part of rainfall that is stored in the root zone and not lost by surface runoff or deep percolation. Using the Aqua Crop model, USDA-SCS procedure was used with formula

$$
\begin{aligned}
& P e_{m}=\left(0.70917 P_{m}^{0.82416}-\right. \\
& 0.11556) 10^{0.02426 E T m}
\end{aligned}
$$

Where, $E T c_{m}$ is the monthly crop evapotranspiration, $\mathrm{P}_{\mathrm{m}}$ is the rainfall and $P e_{m}$ is the monthly effective rainfall.

\section{Estimation of crop yield using AQUACROP}

Aqua Crop model is based on the crop growth engine which is basically water driven, in which, the crop growth and production are driven by the amount of water used through consumptive use of the plant. Among the empirical function approaches, [12] represented an important source to determine the yield response to water of field, vegetable and tree crops, through the following equation [12].

$$
\frac{Y x-Y}{Y x}=K y\left(E T x-\frac{E T}{E T x}\right)
$$

Where, $\mathrm{Y}_{\mathrm{x}}$ and $\mathrm{Y}$ are the maximum and actual yield, $\mathrm{ET}_{\mathrm{x}}$ and ET are the maximum and actual evapotranspiration, and Ky is the proportionality factor between relative yield loss and relative reduction in evapotranspiration.

$$
\begin{gathered}
\begin{array}{c}
\text { Estimation of water foot print } \\
\text { Water footprint }=\frac{C W R}{Y}
\end{array} \\
W F_{\text {blue }}=\frac{C W R_{\text {blue }}}{Y} \\
W F_{\text {green }}=\frac{C W R_{\text {green }}}{Y}
\end{gathered}
$$

Where CWU is the crop water use and Y is the crop yield.

Planting dates.

This was determined as March to July and September to December basing on the cropping calendar of the scheme.

\section{Crop productivity.}

Irrigation data and fertilizer application data was collected from the farmers and then input in the Aqua Crop model.

Soil parameters were estimated based on the in-situ test and feel method.

\section{To formulate farm-water management strategies to minimize water footprint.}

Aqua Crop simulation model was used to formulate different management scenarios, so as to come up with water management strategies to minimize water footprint.

Irrigation at; $60 \%, 80 \%, 100 \%, 120 \%$ of the crop water requirement.

\section{RESULTS AND DISCUSSIONS}

Compared to the maximum permissible effluent levels, the total phosphates discharged from the rice scheme were within the range. The $\mathrm{pH}, \mathrm{COD}$, Magnesium, Calcium were also within the permissible ranges by NEMA.

\begin{tabular}{|l|l|}
\hline Location/ sample point & Discharge, $Q\left(\mathrm{~m}^{3} / \mathrm{s}\right)$ \\
\hline Main diversion from River Manafwa & 9.140 \\
\hline Kapisa intake point & 7.777 \\
\hline Diversion to DRIS & 7.133 \\
\hline Field canal (around Block 1A) & 0.338 \\
\hline
\end{tabular}


From the above results, the discharge of water into the scheme at Kapisa intake point is 7.777 cumecs. The amount of water diverted to DRIS is 7.133 cumecs, which is then supplied to the 10 blocks of DRIS. The amount of water used up in the scheme in the 150 growing days of rice was as $7.133 * 3600 * 24 * 150=92,443,680 \mathrm{~m}^{3} /$ season. The Grey water footprint for the first season was found out to be 500 $\mathrm{m}^{3} /$ ha and $129.87 \mathrm{~m}^{3} /$ ton. A GWF larger than zero does not imply that the ambient water quality standards are violated, it shows that part of the assimilation capacity has been consumed. From this study, a total of $129.87 \mathrm{~m}^{3} /$ ton is required to dilute the Nitrogen levels to suit the ambient water quality of waste water by NEMA. The GWF for this season was found to be $143.39 \mathrm{~m}^{3} /$ ton. This implies for every ton, $143.39 \mathrm{~m}^{3}$ of water is needed to dilute the nutrients for River Manafwa to maintain its natural concentration CWUgreen which is the amount of rain water used up by the rice was $414.9 \mathrm{~mm}$ multiplying it with 10 which is a factor for converting water depth(mm) into water volume per hectare $\left(\mathrm{m}^{3} / \mathrm{ha}\right)$. The green water footprint was higher than that of the blue water footprint. this means that rain water was more used than the irrigation water. The yield dropped in this season to 3.487 ton/ha. This was due to the supplementary use of irrigation water. Irrigated crops receive more nutrients than rainfed crops. ET water productivity is an indicator of how well water was used in production of yield

\begin{tabular}{llllll}
\hline Treatment & total water applied & water saved & \% water saved & ET WP & Yield \\
\hline $\mathbf{6 0}$ & & & & 3.805 \\
$\mathbf{8 0}$ & 256.41 & 170.94 & 40 & 0.93 & 7.85 \\
$\mathbf{1 0 0}$ & 341.88 & 85.47 & 0 & 1.94 & 7.467 \\
$\mathbf{1 2 0}$ & 427.35 & 0 & -20 & 0.9 & 3.730 \\
& 512.82 & -85.47 & & & \\
\hline
\end{tabular}

From the above results, a treatment of $120 \%$ yielded the lowest productivity of 0.9 , at $100 \%$ the water productivity was $1.94 \mathrm{~kg} / \mathrm{m} 3$ and yield 7.467 ton $/ \mathrm{ha}$. At $80 \%$, the water productivity was 1.85 and yield of 7.465 ton/ha. At $60 \%$, the water productivity further declined to $0.93 \mathrm{~kg} / \mathrm{m} 3$ and the yield was 3.805 ton/ha. This implies that at a deficit irrigation of $80 \%$ of what the crop requires, the yield is relatively high almost up to $100 \%$ of what is given to the crop.

\section{CONCLUSION}

Water footprint assessment not only accounts for the water consumed but also the sustainability of water use. Aqua crop model was used as a simulation tool. The blue and green water footprints were considered for the different growing seasons of DRIS according to the cropping calendar. Green water footprint was computed using the volume of green water divided by the crop yield. Blue water footprint was estimated with the volume of blue water use divided by the crop yield. Blue water use was less due to high amount of rainfall; the irrigation requirement was reduced. The grey water footprint was estimated based on the application of Nitrogen fertilizer to crops. This was because of its intensive application during the field management practices in rice growth.

\section{REFERENCES}

[1] WWAP (United Nations World Water Assessment Programme) Water in a Changing World | United Nations Educational, Scientific and Cultural Organization. 2009.

[2] Firda AA, Purwanto. Water Footprint Assessment in the Agroindustry: A Case Study of Soy Sauce Production. E3S Web Conf 2018;31:2017-9. doi:10.1051/e3sconf/20183108018.

[3] Hoekstra AY, Chapagain AK, Aldaya MM, Mekonnen MM. The Water Footprint Assessment Manual. Setting the Global Standard. vol. 31. 2011. doi:10.1080/0969160x.2011.593864.

[4] Hoekstra AY, Chapagain AK, Aldaya MM, Mekonnen MM Water footprint manual. State Art 2009.

[5] Shi C, Wang Y, Zhang C, Zhang L. Spatial-temporal differences in water footprints of grain crops in Northwest China: LMDI decomposition analysis. Water (Switzerland) 2019;11. doi:10.3390/w11122457.

[6] Zeng Z, Liu J, Koeneman PH, Zarate E, Hoekstra AY. Assessing water footprint at river basin level: A case study for the Heihe River Basin in northwest China. Hydrol Earth Syst Sci 2012;16:2771-81. doi:10.5194/hess-16-2771-2012.

[7] MWE. A National Irrigation Master Plan for Uganda(20102035). 2011.

[8] Angella N. Farmers' Willingness To Pay For Irrigation Water:The Case Of Doho Rice Irrigation Scheme In Eastern Uganda. Makerere University, 2014.

[9] Bwambale E, Home PG, Raude JM, Wanyama J. Development of a Water Allocation Model for Equitable Water Distribution at Doho Rice Irrigation Scheme, Uganda Email address: 2019;7:62-9. doi:10.11648/j.hyd.20190704.12.

[10] Environmental Protection Agency. EPA Progress Report 2010 2010:205-26.

[11] Allen RG, Pereira LS, Raes D, Smith M. FAO Irrigation and Drainage Paper No. 56 - Crop Evapotranspiration 1998.

[12] Steduto P, Theodore c. H, Fereres E, Raes D. Crop yield response to water. Rome, Italy: 2012. 